\title{
Surgical Approaches in Odontogenic Orbital Cellulitis (OOC): Our Experience and Review of Literature
}

\author{
Romano Antonio $^{1}$ - Troise Stefania $^{1}$ - Committeri Umberto ${ }^{1} \cdot$ Arena Antonio $^{1}$. \\ Giovanni Dell'Aversana Orabona $^{1,3} \cdot$ Seidita Francesco $^{1} \cdot$ Bonavolontà Paola $^{1}$. \\ Iaconetta Giorgio $^{2}$ Califano Lugi ${ }^{1}$
}

Received: 2 March 2021 / Accepted: 17 April 2021 / Published online: 2 May 2021

(C) The Author(s) 2021

\begin{abstract}
Aims Odontogenic orbital cellulitis represents a complication of root infections of upper pre-molars and molars. The severity depends on the orbital structure involved. The treatment is based on antibiotic therapy associated or not to surgery. Through the presentation of three cases and a review of literature, we purpose as aim of our study to underline the necessity of a timely diagnosis and to provide the correct surgical approach in each different types and stages of orbital infections. Methods We present three patients that were affected by dental infection evolved in orbital cellulitis. In two cases the disease was solved with the extraction of infected tooth and a surgical endoscopic drainage of the abscess through antrostomy of maxillary sinus. In the third patient the disease had already induced a bulbar perforation and endophthalmitis, so an orbit evisceration was necessary. Results Review of literature showed that the standard treatment of orbital cellulitis is the transnasal approach associated or not by a transoral and/or transcutaneous procedure depending on the stage of the disease and on the causes. In our 3 cases these indications were followed without relapses of the disease. Conclusion An early diagnosis is mandatory in odontogenic orbital cellulitis specially to avoid serious
\end{abstract}

Giovanni Dell'Aversana Orabona

maxillounina@gmail.com

1 Department of Maxillofacial Surgery, Federico II University of Naples, Via Pansini, 5, 80131 Naples, Italy

2 Neurosurgery Department, University of Salerno, Via Giovanni Paolo II, 132, 84084 Fisciano, Salerno, Italy

3 Department of Neuroscience and Reproductive and Odontostomatological Sciences, Maxillofacial Surgery, School of Medicine, University of Naples "Federico II", Via Sergio Pansini, 5, 80131 Naples, Italy complications. Surgical treatment can be simple and effective mostly in early-stage infection: it is based on extraction of infected tooth and on the drainage of abscess. Surgical approach consists in transnasal procedure flanked or not by transoral and transcutaneous procedures based on the stage of the infection considering involved structures.

Keywords Odontogenic orbital cellulitis .

Surgical approach $\cdot$ Dental extraction $\cdot$ Early diagnosis

\section{Introduction}

Orbital cellulitis (OC) and subperiosteal abscess (SPA) represent an inflammatory disorder that occur to orbital tissues. These conditions admit many causes, mainly: trauma, orbital foreign body, dacryocystitis and endophthalmitis [1,2].

Approximately not more $2-5 \%$ of cases of $\mathrm{OC}$ are odontogenic (OOC). In this rare case the $\mathrm{OC}$ is configured as a complication relative to a root infection of upper premolars and molars. The root would be directly in contact with the maxillary sinus floor mucosae, providing a passage of microorganisms. In this way, the odontogenic bacterial infection spread to the orbit through the paranasal sinuses. In the most serious cases, a central spread of the infection that induces then an intracranial sequela such as cavernous sinus thrombosis, meningitis, and encephalitis is possible [3].

Microbial cultures of orbital cellulitis typically show polymicrobial infections, including anaerobic Bacteroides species, streptococcus, in particularly Streptococcus Pyogenes and Pneumoniae, Prevotella, Fusobacterium and, in children, Hemophilus influenzae. Organisms 
most reported include Staphylococcus Aureus and alfa hemolytic Streptococcus [3, 4].

Clinically, orbital cellulitis begins with general and nonspecific signs and symptoms such as severe eyelid redness and edema, ptosis, conjunctival chemosis, discharge, erythema of periorbital tissues, and periocular pain or pain due to eye movements. As soon as the infection progresses, there are specific signs such as proptosis and globe displacement, dystopia, decreased vision, impaired color vision, and limited ocular motility. In the cases of odontogenic origin, there are symptoms of dental involvement, such as face and cheek swelling, teeth and face pain, bad breath and dental hypersensitivity [5].

In radiological imaging the first step is represented by orthopantomography (OPG) that evaluates the involvement of the dental elements. II level of evaluation is Computerized Tomography (CT) helpful to identify the sinuses involvement, orbital abscesses, and any cerebral complications. Magnetic Resonance Imaging (MRI) can be useful in evaluation of the retro-maxillary soft tissues and cavernous sinus.

Thanks to the anatomical district of "orbital septum", which is configured as the most anterior extension of the periosteum side of the orbit, the OC are classified in: preand post- septal.

Pre-septal inflammation shows eyelid edema in the absence of orbital signs. It is caused by a direct inoculation of the pathogenic microbes through a skin infection. Swelling of the eyelid remains anterior to the orbital septum and it is the result of the impeded venous and lymphatic drainage.

In post-septal inflammation, the orbital tissue is diffusely infiltrated by inflammatory cells and bacteria. According to the posterior orbit and cerebral involvement, the degree of proptosis, the visual impairment and other complications change $[6,7]$.

In 1970, Chandler et al. classified orbital cellulitis and their complications based on localization and severity of the infection [4] (Table 1).

Historically, this classification based on the severity of clinical and radiological images has been useful in order to differentiate the affected structures and, therefore, the treatment. Pre-septal cellulitis responds to antibiotics alone while Orbital cellulitis or sub-periosteal abscess require a surgical procedure, from the incision and drainage of the periapical abscess or tooth extraction, to endoscopic sinus surgery until to an evisceration surgery. Currently, endoscopy is considered a valid instrument that respects the functionality of the paranasal sinuses, without altering the anatomy of the ciliated epithelium inside [8].

The aim of our article is to point up the importance of early diagnosis of the disease, the prompt identification of the odontogenic origin and the use of a correct surgical algorithm, to quickly remove the cause of the infection. We present three cases in different stages of orbital infection, and we attempt to choose, through a brief review of the literature, the most appropriate surgical approach, based on the different stages of the disease.

\section{Material and Methods}

This study was granted an ethical exemption by Federico II University, Naples, Italy, due to its retrospective nature. We present three cases of patients affected by odontogenic orbital cellulitis, admitted to our Department of MaxilloFacial Surgery between November 2017 and July 2018. We also analyzed the most recent retrospective studies, on the topic of surgical approaches of odontogenic orbital cellulitis, in the literature from 2001 to 2019 with more than 10 cases described and we realized a brief review.

\section{Case Series}

\section{Case 1, Group 2: Orbital Cellulitis (OC)}

A 49-year-old man was hospitalized in our Department of Maxillo-Facial Surgery of the Federico II University of Naples on April 2018. For four days, the patient had complained a swelling of the lower eyelid in the right eye. At the clinical examination, in the right eye there was evidence of conjunctival chemosis, hyperemia, exophthalmos, and dystopia. Ocular motility and eye reflexes were preserved. The left eye did not show signs or symptoms of infection.

Computed Tomography (CT) of paranasal sinuses and orbit, revealed that right maxillary sinus, ipsilateral nasal fossa, ethmoid cells, and medial region of the orbit were occupied by inflammatory tissue. Soft tissue edema was also present in the orbital section. The oral examination revealed the presence of a caries of the 1.6 dental element; the orthopantomography (OPT) confirmed the caries and revealed a root involvement, as well as peri-radicular tissues. A nasal fibroscopy revealed purulent inflammation in the right inferior, middle, and superior meatus, and in right uncinate process. (Fig. 1).

Based on the clinical and radiological characteristics, the patient belonged to the second group of the Chandler's classification with an odontogenic infection; so, our plane was combined antibiotic and surgical treatment.

The patient was treated, at first, with empiric antibiotic therapy (Ceftriaxone $2 \mathrm{~g}$ iv 1/die, Levofloxacin $500 \mathrm{mg}$ Intravenous (IV) 1/die, Metronidazole $500 \mathrm{mg} \mathrm{IV} 1 /$ die and topic Tobramycin). Then the cultural and blood tests revealed a polymicrobial infection with predominance of 
Table 1 Chandler classification, based on localization and severity of the infection, permits to value orbital cellulitis and their possible complications

\begin{tabular}{ll}
\hline Chandler's Classification & \\
\hline Group 1: Preseptal cellulitis & $\begin{array}{l}\text { The inflammatory process is limited anteriorly to the orbital septum and does not invade the infraorbital } \\
\text { structures }\end{array}$ \\
\hline $\begin{array}{l}\text { Group 2: Orbital cellulitis } \\
\text { (OC) }\end{array}$ & The orbital tissues are diffusely affected \\
$\begin{array}{l}\text { Group 3: Subperiosteal } \\
\text { abscess (SPA) }\end{array}$ & Purulent material collects in periorbital tissues, between the bony walls of the orbit and the periorbita \\
$\begin{array}{l}\text { Group 4: Intraorbital abscess } \\
\text { (IOA) }\end{array}$ & $\begin{array}{l}\text { There is a purulent collection inside the orbit } \\
\text { Group 5: Cavernous sinus } \\
\text { thrombosis }\end{array}$ \\
$\begin{array}{l}\text { There is an extension of orbital inflammation into the cavernous sinus that can lead to involvement of the third, } \\
\text { fifth, and sixth cranial nerves }\end{array}$
\end{tabular}

Fig. 1 Case 1: Presurgical frontal photo: limitation movement of right eye not consensual with the left one (a) and CT Imaging in coronal section: maxillary sinus occupied by abscess $(*)$, periorbital inflammatory degeneration of tissues $(\S)(\mathbf{b})$

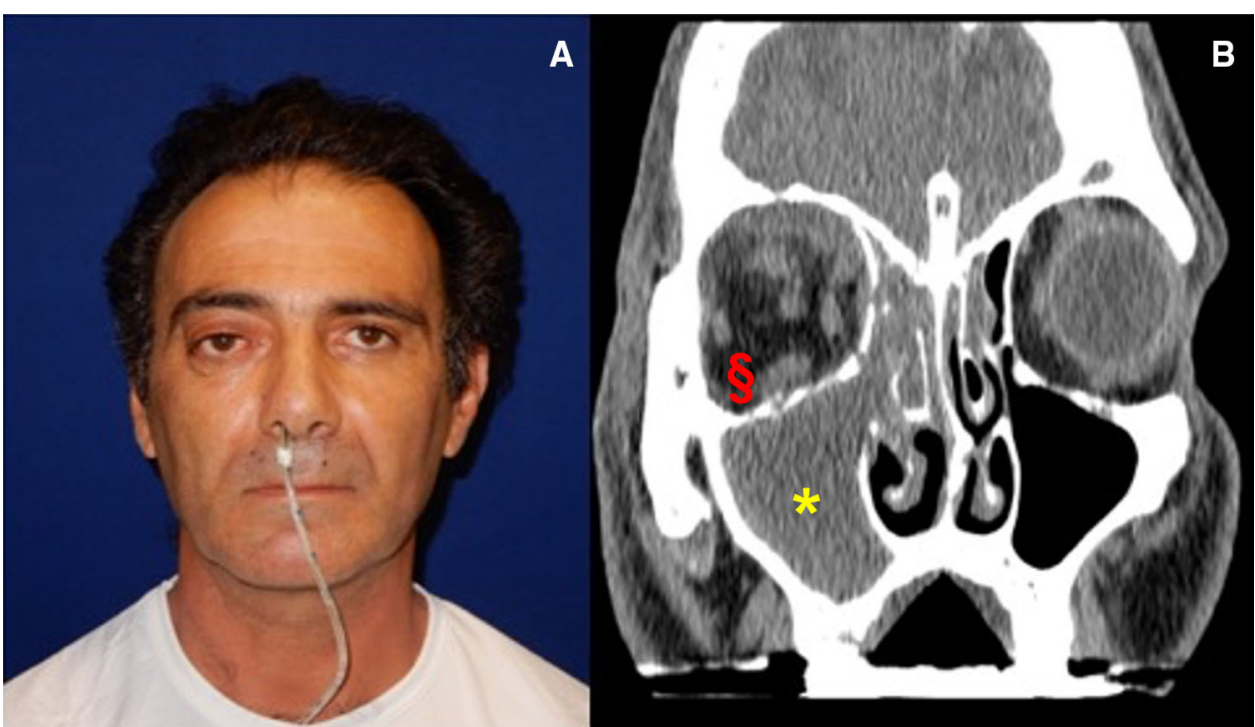

Bacterioides species, so after consulting with Infectious Disease Department, the therapy dosed was: Vancomycin $500 \mathrm{mg}$ IV four times in die (Q.I.D.), Levofloxacin $500 \mathrm{mg}$ IV twice a day (B.I.D.), Metronidazole $500 \mathrm{mg}$ IV every day (Q.D.) and topical Tobramycin. A week later, the patient showed a clinical improvement and underwent surgical procedure based on a 1.6 dental element extraction, and endoscopic antrostomy of the right maxillary sinus ostium and anterior ethmoidectomy, with drainage of the purulent material.

The patient was discharged with antibiotic oral therapy, steroids, saline solution nasal washes, and oral hygiene advices. During follow-up examination (one week, one month, six months and one year), the endoscopic and CT controls showed reduction of inflammation and the patient had no relapse of the infection (Fig. 2.)

\section{Case 2, Group 3: Subperiosteal Abscess (SPA)}

A 17-year-old male was hospitalized on July 2018 in the Orbital Surgery Unit of the Ophthalmologic Department of the Federico II University of Naples; one week before the patient complained swelling on the upper and lower eyelids in the left eye. At clinical examination there was evidence of conjunctival chemosis, exophthalmos and dystopia. Ocular and lower eyelid itch were referred and limitation in ocular motility were observed. The eye reflexes were preserved. The right eye did not show signs or symptoms of infection.

Magnetic Resonance Imaging (MRI) of paranasal sinuses and orbit revealed the presence of inflammatory tissue in frontal-ethmoidal-maxillary sinuses that induced an erosion of medial wall of the orbit, and dislocation of medial rectus muscle. Soft tissue edema was also present in the orbit. Coronal slices showed a subperiosteal abscess, all along the medial wall of the left orbit and orbital cellulitis. 
Fig. 2 Case 1: Postsurgical photo of patient in frontal section: rehabilitation of consensual extrinsic motility of the eyes (a) and CT Imaging in coronal section: maxillary sinus empty of abscess secretions (*), periorbital edema reduction $(\S)$, site of antrostomy (\#) (b)

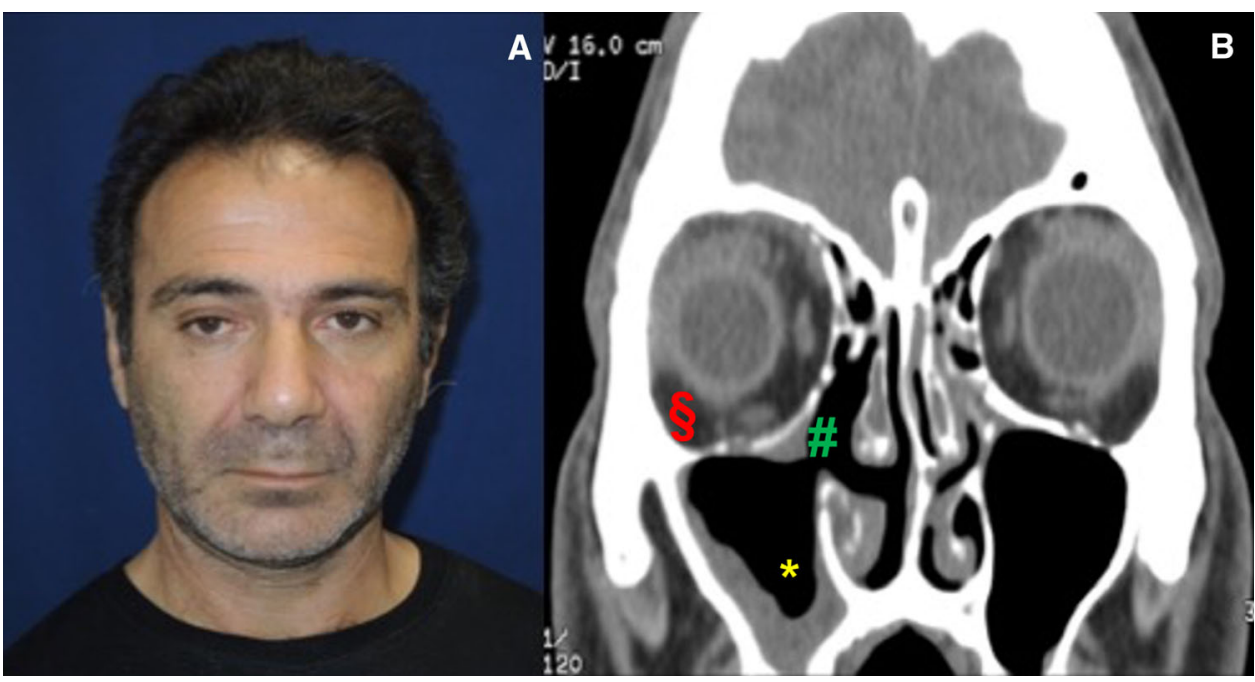

The oral examination revealed the presence of a solution of continuity of the enamel on the 2.6 dental element. The panoramic radiograph confirmed the presence of caries and showed a periapical lesion of $3 \mathrm{~mm}$. Nasal fibroscopy revealed purulent inflammation in the left inferior and middle meatus.

Based on the clinical and radiological characteristics, the patient belonged to the third group of the Chandler's classification, hence our plane was combined antibiotic and surgical treatment (Fig. 3).

The patient immediately initiated an empiric antibiotic therapy (Vancomycin $500 \mathrm{mg}$ iv Q.I.D., Levofloxacin $500 \mathrm{mg}$ IV B.I.D., Metronidazole $500 \mathrm{mg}$ IV Q.D. and topical Tobramycin). Cultural blood tests revealed polymicrobial infection with presence of
Staphylococcus aureus and Infectious Disease Department confirmed the therapy. After a week the patient showed a clinical improvement, therefore he underwent 2.6 dental element extraction followed by endoscopic antrostomy of the left maxillary sinus ostium, anterior and posterior ethmoidectomy, with drainage of the purulent material according to DRAF 1 technique (it includes the resection of the Uncinate process in addition to the resection of medial lamella of the Agger Nasi cell and the anterior wall of the ethmoid bulla) and a superior, middle and inferior turbinoplasty.

The patient was discharged with antibiotic therapy, steroids, saline solution nasal washes, and oral hygiene advices. During follow-up examination (one week, one month, six months and one year) the endoscopic and MRI
Fig. 3 Case 2: Presurgical photo of patient in frontal section: swelling from abscess collection to supero-medial localization in the left orbit (a) and MRI Imaging in coronal section: maxillary sinus occupied by abscess $(*)$, periorbital inflammatory degeneration of tissues $(\S),(\mathbf{b})$

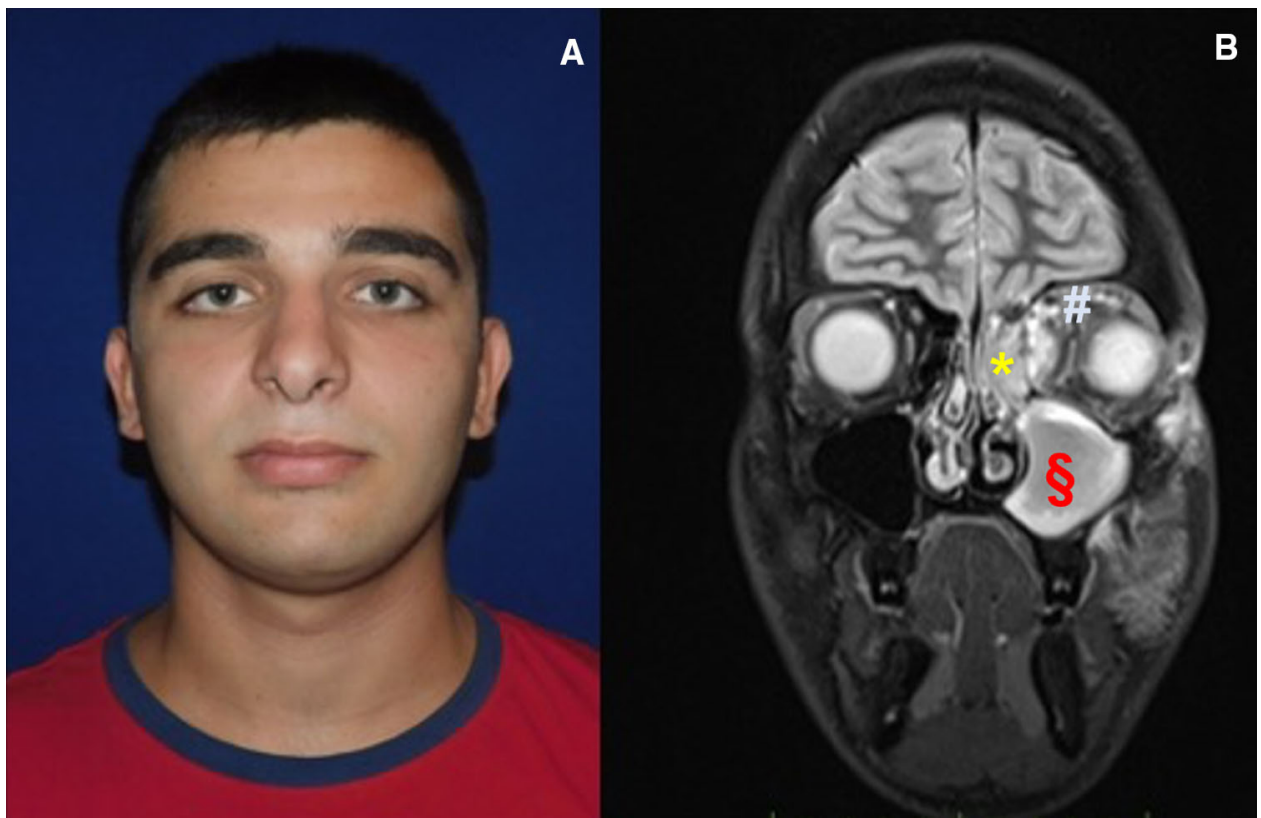


controls showed reduction of inflammation and the patient had no relapse of the infection (Fig. 4).

\section{Case 3, Group 4: Infraorbital Abscess (IOA)}

A 50-year-old woman was referred to the Department of Maxillo-Facial Surgery of the University Federico II of Naples on November 2017 [9].

She was previously referred to another hospital with a history of rapidly progressive inflammation in the right orbit, not responsive to antibiotic and corticosteroid therapy. At hospitalization, she had bulbar perforation and fever, but hemodynamically stable. The clinical examination of the right orbit revealed proptosis, superior and inferior eyelid swelling, and erythema. There was a complete opening limitation of eye. The eye was hypotonic and partially covered by a conjunctival patch. The conjunctiva was hyperemic and chemotic, and there was also severe corneal edema. Anterior chamber, lens, vitreous and retina were not assessable, due to corneal opacity. Visual acuity in the right eye was only scanty light perception. The left eye was normal, with no signs or symptoms of infection. MRI of head and neck, sinuses and orbit, revealed an important right infraorbital abscess with optical nerve involvement, displacement of extrinsic muscles, and right maxillary sinus empyema, extending to right anterior and posterior ethmoidal cells. The oral examination revealed very scanty oral hygiene, with tartar and dental plaque, dental caries and diffuse periodontal disease the orthopantomography (OPT) demonstrated horizontal and vertical bone loss, periodontal disease and dental caries. These findings were compatible with an odontogenic infection. According to the clinical and radiological characteristics, the patient belonged to the fourth group of the Chandler's classification, and our plane was combined antibiotic and surgical treatment. (Fig. 5).

The patient was immediately treated with empiric antibiotic therapy (Ceftriaxone $2 \mathrm{~g}$ IV 1/die, Levofloxacin $500 \mathrm{mg}$ IV B.I.D., Metronidazole $500 \mathrm{mg}$ iv Q.D. and topic Tobramycin). A sample of orbital fluid was obtained and analyzed. The cultural exam revealed Propionibacterium spp and Bacteroides spp. With the agreement of the Infectious Disease Department, the therapy was modified to Vancomycin $500 \mathrm{mg}$ IV Q.I.D., Levofloxacin $500 \mathrm{mg}$ IV B.I.D., Metronidazole $500 \mathrm{mg}$ IV Q.D. and topical Tobramycin. The patient showed a clinical improvement, nonetheless the eye condition did not enhance. For this reason, an urgent surgical removal of the eyeball was performed, in order to avoid the high risk of intracranial complications. After eye surgery, the patient underwent a complete dental extraction.

The patient was discharged with antibiotic oral therapy, steroids, saline solution nasal washes, and oral hygiene advices. During follow-up examination (one week, one month, six months, and one year) the endoscopic and MRI controls, showed reduction of inflammation and the patient had no relapse of the infection in the right orbit, paranasal sinuses and oral cavity. (Fig. 6.)

\section{Discussion}

Orbital cellulitis commonly occurs (84\% of cases) from bacterial infections; other causes are periorbital trauma, periocular infections, orbital surgery, ascending thrombophlebitis. Many reasons predispose the tissues of the
Fig. 4 Case 2: Postsurgical photo of patient in frontal section: resolution of swelling induced by abscess in superomedial section of the left orbit (a) and MRI Imaging in coronal section: maxillary sinus totally empty (§), rehabilitation of periorbital tissues (\#), ethmoid site drained of purulent secretions $(*)(\mathbf{b})$

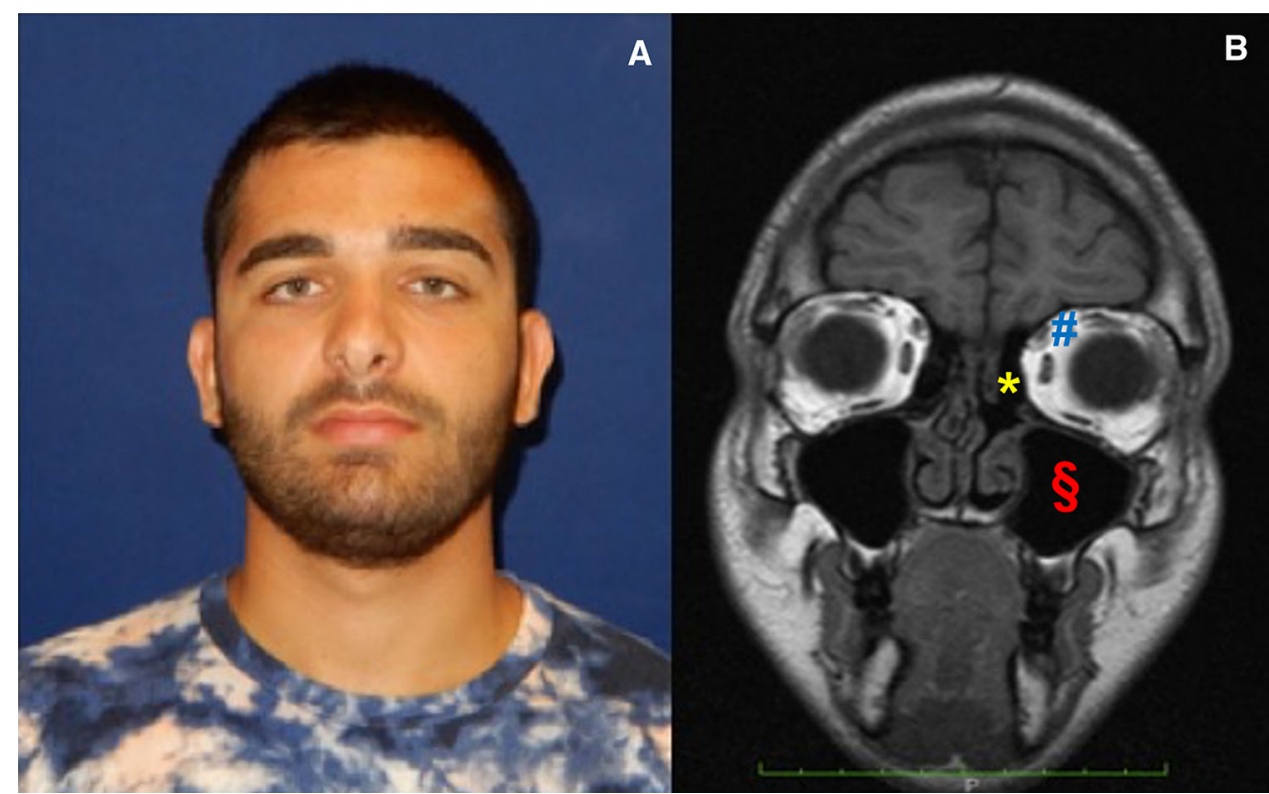




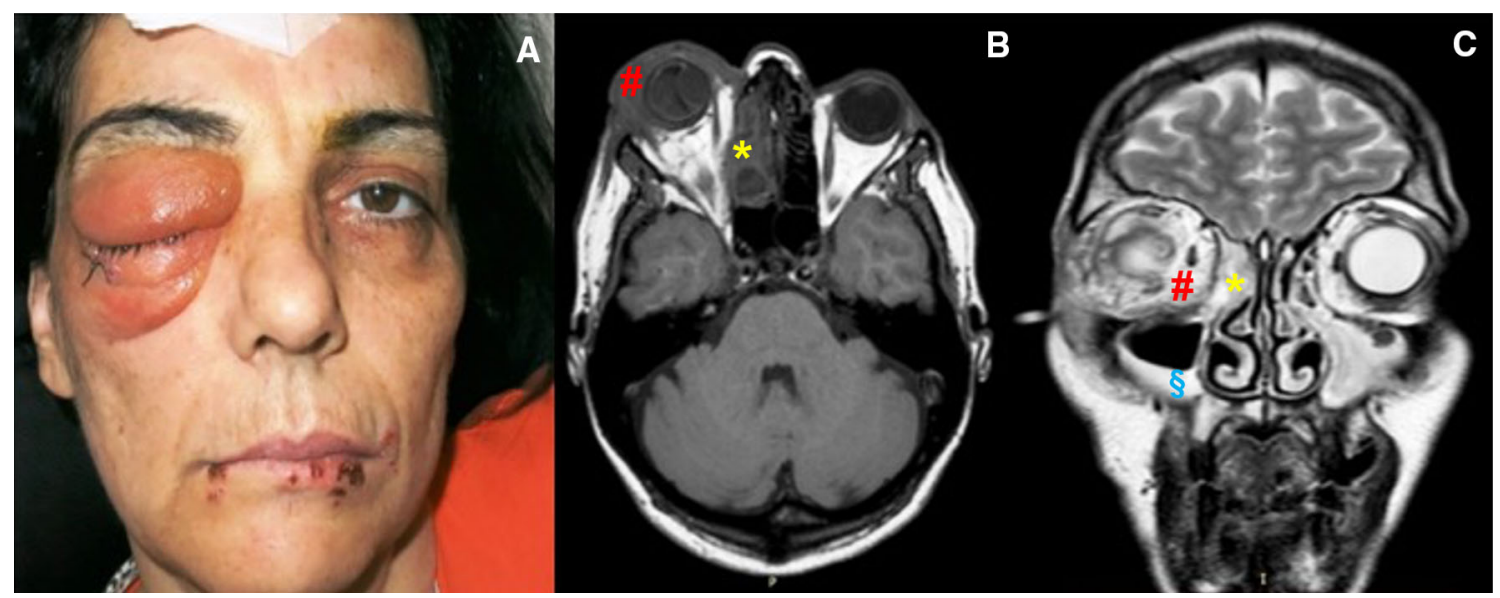

Fig. 5 Case 3: Presurgical photo of patient in frontal section (a) and MRI Axial section (b) and MRI Coronal section (c): ethmoid abscess (*), hyper-haemic maxillary sinus mucosa (§), orbital abscess (\#)

Fig. 6 Case 3: Postsurgical photo of patient in frontal section: closed eyelid (a), open eyelid showing orbit evisceration (b), MRI in Axial section (c) and MRI Coronal section (d): ethmoid sinus drained of purulent secretions $(*)$, maxillary sinus totally empty (§), resolution of the orbital abscess (\#)

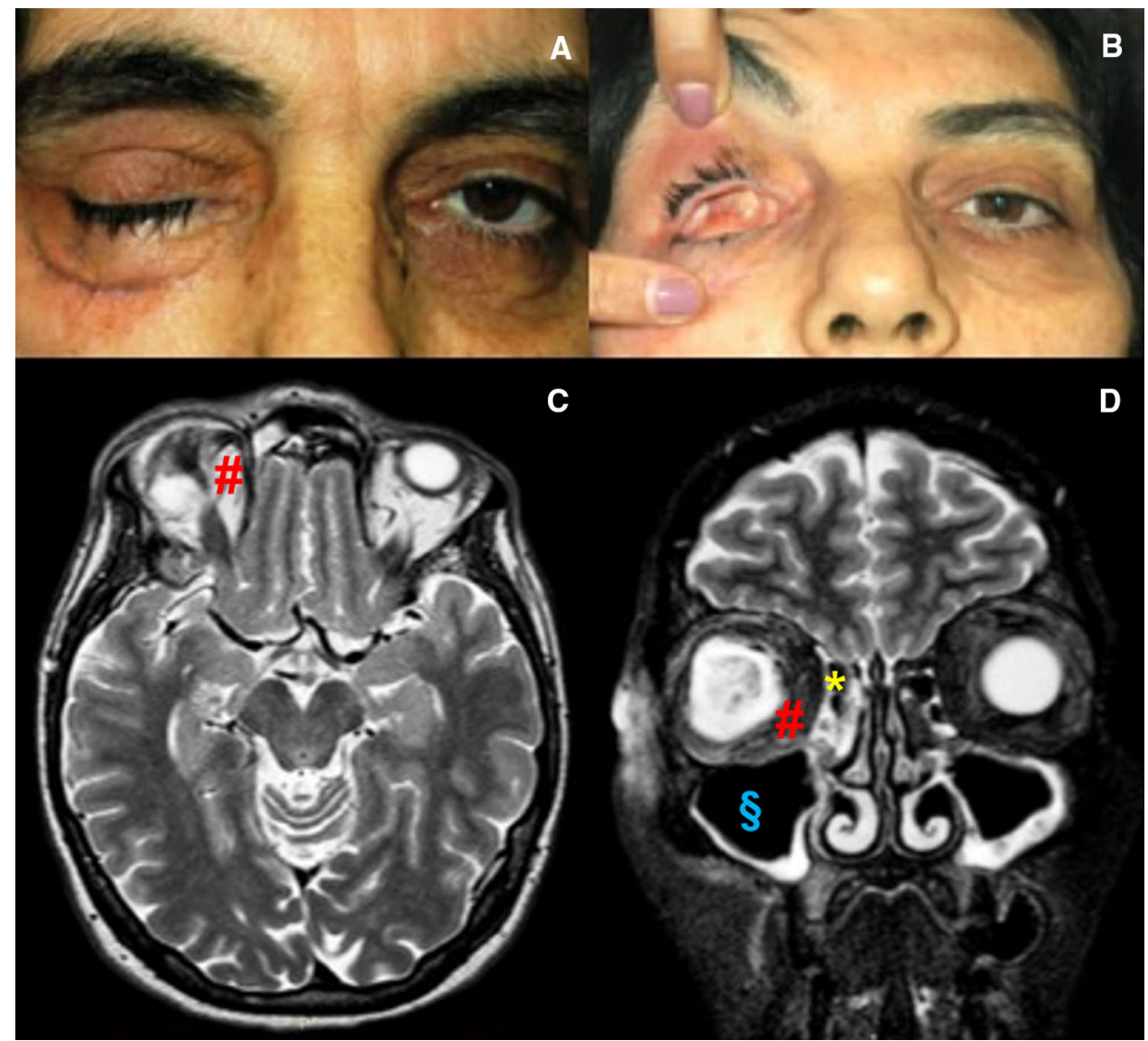

orbital region to serious consequences when an infection spreads: in particular the "closed box" anatomy of the orbit and the poor lymphatic drainage cause the stagnation of access and its extension in the pre-septal and periorbital area.

Odontogenic orbital cellulitis (OOC) is uncommon, but it is a potential cause of severe complications. OOC approximately represent 2-5\% of cases of orbital cellulitis: it usually occurs when the integrity of the Schneiderian's membrane of paranasal sinuses is interrupted by odontogenic disease or after dental procedures, such as implant placement, tooth extraction, caries, delayed eruption, endodontic procedures, and sinus lifts [5]. Felisati et al. [10] proposed a division in categories according to initial 
dental treatment: group I, pre-implant treatment; group II, implantology treatment; and group III, dental treatment. According to these categories, the Authors suggested a different approach based on transoral procedure and/or endoscopic surgery.

There are several ways through which an odontogenic infection can spread to the orbit. Root apices are anatomically proximal to adjacent muscle, connective tissue, and sinuses. First, the infection can pass through the maxillary or ethmoidal sinuses because of bone erosions or dehiscence, and it can spread in the orbital floor, the infraorbital neuromuscular canal or in the lamina papyracea. Second, the infection can enter the posterior orbit, directly through the inferior orbital fissure after the penetration of the pterygopalatine and infratemporal fossae. Third, the valveless nature of the venous system of the orbit facilitates the dissemination of the infection. Last, the odontogenic infection can complicate with the perforation of eyelid reaching therefore the pre-septal space and subsequently the orbit $[11,12]$.

Medical management focuses primarily on aggressive antibiotic therapy [13]. Adjunctive use of corticosteroids is considered favorable, except in cases of fungal infection, or in immunocompromised individuals.

In this paper we try to obtain surgical treatment data from the most recent literature, based on different stages of infection. Several Authors have reported the importance of endoscopic surgery flanked by transcutaneous drainage with external approach and intraoral procedures, as shown in Table 2. We also reported the percentage of failures, according to the surgical procedure, in terms of disease recurrence, need for reoperation, and complications. The analysis of the literature reveals that the treatment of choice is Functional Endoscopic Sinus Surgery (FESS) which can be combined with a transcutaneous and/or intraoral approach in some specific cases.

In particular, Tsirouki et al. [13] suggested surgical treatment in presence of severe signs, such as compromised vision, pupillary changes, raised intraocular pressure, proptosis more than $5 \mathrm{~mm}$, failure to respond to medical therapy, concurrent paranasal or frontal sinus infection, intracranial complications and clear dental source of the infection. Garcia et al. [14] recommended surgical procedure for dental infection because of the spread of anaerobes; the involved dental element can be treated by apicectomy or extraction. Felisati et al. [10] included transoral approach also to close oro-antral communications (OAC), to remove dislocated/failed implants, or to approach critical areas (i.e. maxillary alveolar recess, canine fossa, palatal region).
Dewan et al. [11] evaluated that pre-septal cellulitis does not require surgical therapy, while subperiosteal abscesses require it; successful transnasal endoscopic surgery is reported in patients with medial subperiosteal orbital abscesses, superolateral extension requires an external approach such as an incision over the superior orbital rim.

Ikeda et al. [15] suggested an external surgery also in subperiosteal abscess located in upper section medially in the orbit, through Lynch incision which offers adequate visibility and effective drainage but leaves more visible scars. In cases of limited view in medial abscesses in children, in addition to transnasal approach, Pelton et al. [16] suggested a transcaruncle approach, with better esthetic outcomes compared to the Lynch incision.

Torretta el al. [17] reported that endoscopic sinus surgery (ESS) has proved to be effective in treating SPA and IOA. Surgical steps include uncinectomy, middle meatal antrostomy, ethmoidectomy (usually anterior in SPA and anterior and posterior in IOA), and penetration of the lamina papyracea. This procedure seems to be appropriate in the case of medial locations (including those with a posterior extension).

In their review of the literature, Tsirouki et al. [12] proposed FESS approach for cases complicated with frontal sinusitis, and reserved evisceration only for patients who had fulminant orbital involvement, such as cases of bulbar perforation or endophthalmitis.

In cases with intracranial complications, surgical treatment is indicated and should be planned promptly after diagnosis: a delayed surgical drainage of brain abscesses is related to high morbidity and mortality. All patients with intracranial extension of the infection, require a combination of two or more surgical procedures: craniotomy, orbital surgery and sinus surgery.

In this study we reported three cases of patients suffering of odontogenic endo-orbital cellulitis. As soon as they arrived at our observation, we performed a careful clinical examination, a radiological study by CT and MRI (to evaluate the extent of the pathology) and an endonasal fibroscopy to evaluate the presence of purulent material inside the sinuses.

We started an empiric intravenous antibiotic treatment and then a therapy based on the antibiogram. In our cases it was necessary to combine antibiotic therapy and surgical treatment, both for the presence of orbital abscesses and for the odontogenic etiology. The surgical procedures that we performed were in agreement with the data obtained from the literature regarding surgical approaches that are summarized in Table 3. 
Table 2 Our review of literature relative to the endoscopic surgery (FESS Functional Endoscopic Sinus Surgery) in the treatment of Orbital Cellulitis (OC), next to the failure rates of the procedures adopted reported by all authors

\begin{tabular}{|c|c|c|c|c|}
\hline Author/Year & Type of study & No of cases & Treatment of orbital cellulitis & $\%$ of failures \\
\hline Trimarchi et al. [5] 2019 & Retrospective study & 37 & $\begin{array}{l}13 \text { FESS } \\
12 \text { FESS + Dental procedure } 9 \text { FESS + Transoral } \\
3 \text { transcutaneous drainage }\end{array}$ & $2.7 \%$ of total failure \\
\hline Felisati et al. [10] 2013 & Retrospective study & 257 & $\begin{array}{l}121 \text { FESS } \\
136 \text { FESS + Transoral }\end{array}$ & $\begin{array}{l}0.8 \% \\
1.5 \%\end{array}$ \\
\hline Dewan et al. [11] 2011 & Retrospective study & 24 & $\begin{array}{l}9 \text { transcutaneous drainage } \\
15 \text { FESS + t.c drainage }\end{array}$ & $\begin{array}{l}55 \% \\
\text { No }\end{array}$ \\
\hline Ikeda et al. [15] 2003 & Retrospective study & 10 & $\begin{array}{l}4 \text { FESS } \\
6 \text { transcutaneous drainage }\end{array}$ & $\begin{array}{l}\text { No } \\
16 \%\end{array}$ \\
\hline Pelton et al. [16] 2003 & Retrospective study & 11 & $\begin{array}{l}1 \text { FESS } \\
4 \text { transcutaneous drainage } \\
6 \text { FESS + t.c drainage }\end{array}$ & $\begin{array}{l}100 \% \\
25 \% \\
\text { No }\end{array}$ \\
\hline Le et al. [18] 2014 & Retrospective study & 30 & $\begin{array}{l}22 \text { FESS } \\
8 \text { transcutaneous drainage }\end{array}$ & $\begin{array}{l}\text { No } \\
12.5\end{array}$ \\
\hline Nation et al. [19] 2017 & Retrospective study & 16 & $\begin{array}{l}12 \text { FESS } \\
2 \text { transcutaneous drainage } \\
2 \text { FESS + t.c drainage }\end{array}$ & $\begin{array}{l}\text { No } \\
\text { No } \\
\text { No }\end{array}$ \\
\hline Oxford et al. [20] 2006 & Retrospective study & 25 & $\begin{array}{l}18 \text { FESS } \\
7 \text { transcutaneous drainage }\end{array}$ & $\begin{array}{l}11.1 \% \\
14.2 \%\end{array}$ \\
\hline Rahbar et al. [21] 2001 & Retrospective study & 14 & $\begin{array}{l}11 \text { FESS } \\
3 \text { t.c drainage }\end{array}$ & $\begin{array}{l}18.2 \% \\
\text { No }\end{array}$ \\
\hline Tabarino et al. [22] 2015 & Retrospective study & 20 & $\begin{array}{l}11 \text { FESS } \\
9 \text { transcutaneous drainage }\end{array}$ & $\begin{array}{l}\text { No } \\
\text { No }\end{array}$ \\
\hline Tanna et al. [23] 2008 & Retrospective study & 13 & $\begin{array}{l}11 \text { FESS } \\
2 \text { transcutaneous drainage }\end{array}$ & $\begin{array}{l}54.5 \% \\
50 \%\end{array}$ \\
\hline Teinzer et al. [24] 2014 & Retrospective study & 37 & $\begin{array}{l}31 \text { FESS } \\
6 \text { FESS + t. c drainage }\end{array}$ & $\begin{array}{l}19 \% \\
16 \%\end{array}$ \\
\hline Yang et al. [25] 2009 & Retrospective study & 13 & $\begin{array}{l}10 \text { FESS } \\
3 \text { transcutaneous drainage }\end{array}$ & $\begin{array}{l}\text { No } \\
\text { No }\end{array}$ \\
\hline
\end{tabular}

We used transnasal endoscopic approach based on maxillary antrostomy and ethmoidectomy (anterior in the first case and anterior and posterior in the second case) with infected dental element extraction. In the third case, evisceration was necessary to avoid intracranial spread, because an infraorbital abscess with bulbar perforation was already present, probably causing a spread of the infection through the cranial nerves and consequently severe intracranial complications. For the odontogenic etiology, we preferred to perform directly the extraction of the dental elements and not apicectomies, to avoid recurrence. Apart from tooth extraction, we avoided a transoral approach because in our three cases there was no evidence of OAC and dental or implant elements dislocated in the maxillary sinus.
Following these medical and surgical protocols, the three patients did not report any recurrence of the disease at follow-up.

\section{Conclusion}

An early diagnosis is essential to implement a correct therapeutic plan and to avoid serious complications in odontogenic orbital cellulitis. Surgical treatment is quite simple but effective, especially in early-stage infections. It must be based on drainage of the orbital abscess and on removal of the odontogenic noxa. Surgical approach depends on the stages of the infection and on the site of involved structures: transnasal approach is preferred but in 
Table 3 Review of literature about surgical approaches in the treatment of Orbital cellulitis (OC), Subperiosteal Abscess (SPA), Infraorbital Abscess (IOA)

\begin{tabular}{ll}
\hline Condition & Treatment \\
\hline Medial OC/SPA/IOA & FESS (Functional endoscopic sinus surgery) \\
- Medial with limited view & OC/SPA: maxillary antrostomy + anterior ethmoidectomy \\
- Medial in children & OA: maxillary antrostomy + ant. and post. ethmoidectomy \\
& Combined FESS + Lynch incision \\
Inferior OC/SPA/IOA & Combined FESS + transcaruncular access \\
Lateral OC/SPA/IOA & FESS \\
Superior OC/SPA/IOA & Lateral eyebrow incision with orbitotomy and drainage \\
Frontal sinus involvment & Superior eyebrow incision with orbitotomy and drainage \\
IOA with bulbar complications & FESS \\
Dental infection (without implant dislocation or Oral antral communication OAC) & Combined FESS + extraction or endodontic treatment \\
Dental infection with: & Combined FESS +: \\
- Implant dislocation & - Transoral implant removal \\
- OAC & - Transoral OAC repair (eventually with local flap) \\
\hline
\end{tabular}

specific cases an external incision or an intraoral approach would be required.

Funding Open access funding provided by Università degli Studi di Napoli Federico II within the CRUI-CARE Agreement. No funding was acquired for this paper.

\section{Declaration}

Conflicts of Interest There are no conflicts of interest to declare.

Ethical Approval No ethical approval was needed. Signed patient consent was all that was required by the hospital.

Informed Consent Signed patient's consents were obtained for surgical procedures, for participating in the study and for publication of the paper. A photographic consent was obtained for each patient: this consent was necessary because the aim of our study was the orbit so it was not possible to hide/fade eyes section from the photos to guarantee the privacy of our patients.

Open Access This article is licensed under a Creative Commons Attribution 4.0 International License, which permits use, sharing, adaptation, distribution and reproduction in any medium or format, as long as you give appropriate credit to the original author(s) and the source, provide a link to the Creative Commons licence, and indicate if changes were made. The images or other third party material in this article are included in the article's Creative Commons licence, unless indicated otherwise in a credit line to the material. If material is not included in the article's Creative Commons licence and your intended use is not permitted by statutory regulation or exceeds the permitted use, you will need to obtain permission directly from the copyright holder. To view a copy of this licence, visit http://creativecommons.org/licenses/by/4.0/.

\section{References}

1. Ferguson MP, Mc Nab AA (1999) Current treatment and outcome in orbital cellulitis. Aust N Z J Ophthalmol 27:375-379

2. De Medeiros EHP, Pepato AO, Sverzut CE, Trivellato AE (2012) Orbital abscess during endodontic treatment: a case report. JOE 38:1541-1543

3. Procacci P, Zangani A, Rossetto A, Rizzini A, Zanette G, Albanese M (2017) Odontogenic orbital abscess: a case report and review of literature. Oral Maxillofac Surg 21(2):271-279

4. Chandler ER (1970) The pathogenesis of orbital complications in acute sinusitis. Laryngoscope 80:1414-1428

5. Trimarchi M, Vinciguerra A, Galli A, Capparè P, Vinci R, Bussi M (2019) Management of upper odontogenic infections and the role of multidisciplinary treatment. J Osseointegr 11(4):548-552

6. Stead TG, Retana A, Houck J, Sleigh BC, Ganti L (2019) Preseptal and postseptal orbital cellulitis of odontogenic origin. Cureus 11(7):e5087

7. De Assis-Costa MD, Santos GS, Maciel J, Sonoda CK, de Melo WM (2013) Odontogenic infection causing orbital cellulitis in a pediatric patient. J Craniofac Surg 24(5):e526-e529

8. Keles N, Ahishali B, Ilicali OC, Değer K (2001) Evaluation of ultrastructural changes in paranasal sinus mucosa after functional endoscopic sinus surgery in patients with chronic rhinosinusitis. Am J Rhinol 15(4):225-229

9. Bonavolontà P, Dell'Aversana Orabona G, Seidita F, Donna P, Committeri U, D'Andrea L, Califano L (2020) A rare case of blindness due to an odontogenic abscess. Chirurgia 33(5):255-259

10. Felisati G, Chiapasco M, Lozza P, Saibene AM, Pipolo C, Zaniboni M, Biglioli F, Borloni R (2013) Sinonasal complications resulting from dental treatment: outcome-oriented proposal of classification and surgical protocol. Am J Rhinol Allergy 27(4):e101-e106

11. Dewan MA, Meyer DR, Wladis EJ (2011) Orbital cellulitis with subperiosteal abscess: demographics and management outcomes. Ophthalmic Plast Reconstr Surg 27(5):330-332 
12. Kim IK, Kim JR, Jang KS, Moon YS, Park SW (2007) Orbital abscess from an odontogenic infection. Oral Surg Oral Med Oral Pathol Oral Radiol Endod 103(1):e1-e6

13. Tsirouki T, Dastiridou AI, Ibánez Flores N, Cerpa JC, Moschos MM, Brazitikos P, Androudi S (2018) Orbital cellulitis. Surv Ophthalmol 63(4):534-553

14. Garcia GH, Harris GJ (2000) Criteria for nonsurgical management of subperiosteal abscess of the orbit: analysis of outcomes 1988-1998. Ophthalmology 107(8):1454-6, Discussion 1457-8

15. Ikeda K, Oshima T, Suzuki H, Kikuchi T, Suzuki M, Kobayashi $\mathrm{T}$ (2003) Surgical treatment of subperiosteal abscess of the orbit: Sendai's ten-year experience. Auris Nasus Larynx 30(3):259-262

16. Pelton RW, Smith ME, Patel BC, Kelly SM (2003) Cosmetic considerations in surgery for orbital subperiosteal abscess in children: experience with a combined transcaruncular and transnasal endoscopic approach. Arch Otolaryngol Head Neck Surg 129(6):652-655

17. Torretta S, Guastella C, Marchisio P, Marom T, Bosis S, Ibba T, Drago L, Pignataro L (2019) Sinonasal-related orbital infections in children: a clinical and therapeutic overview. J Clin Med 8(1): 101

18. Le TD, Liu ES, Adatia FA, Buncic JR, Blaser S (2014) The effect of adding orbital computed tomography findings to the Chandler criteria for classifying pediatric orbital cellulitis in predicting which patients will require surgical intervention. J Am Assoc Pediatr Opthalmol Strabismus 18(3):271-277

19. Nation J, Lopez A, Grover N, Carvalho D, Vinocur D, Jiang W (2017) Management of large-volume subperiosteal abscesses of the orbit: medical vs surgical outcomes. Otolaryngol Head Neck Surg 157(5):891-897

20. Oxford LE, McClay J (2006) Medical and surgical management of subperiosteal orbital abscess secondary to acute sinusitis in children. Int J Pediatr Otorhinolaryngol 70(11):1853-1861

21. Rahbar R, Robson CD, Petersen RA, DiCanzio J, Rosbe KW, McGill TJ, Healy GB (2001) Management of orbital subperiosteal abscess in children. Arch Otolaryngol Head Neck Surg 127(3):281-286

22. Tabarino F, Elmaleh-Bergès M, Quesnel S, Lorrot M, Van Den Abbeele T, Teissier N (2015) Subperiosteal orbital abscess: volumetric criteria for surgical drainage. Int J Pediatr Otorhinolaryngol 79(2):131-135

23. Tanna N, Preciado DA, Clary MS, Choi SS (2008) Surgical treatment of subperiosteal orbital abscess. Arch Otolaryngol Head Neck Surg 134(7):764-767

24. Teinzer F, Stammberger H, Tomazic PV (2015) Transnasal endoscopic treatment of orbital complications of acute sinusitis: the Graz concept. Ann Otol Rhinol Laryngol 124(5):368-373

25. Yang M, Quah BL, Seah LL, Looi A (2009) Orbital cellulitis in children-medical treatment versus surgical management. Orbit 28(2-3):124-136

Publisher's Note Springer Nature remains neutral with regard to jurisdictional claims in published maps and institutional affiliations. 